\title{
Hubungan keterlibatan ayah dalam pengasuhan dengan kecerdasan emosional remaja
}

\author{
Ayu Ratna Sari*, Riau Roslita, Yecy Anggreny \\ Program Studi Sarjana Keperawatan STIKes Hang Tuah Pekanbaru \\ ayuratnaa98@gmail.com \\ *Correspondent Author
}

\section{Article history}

Received 30 September 2020

Revised 15 November 2020

Accepted 23 Februari 2020

Keywords

Emotional intelligence

Father's involvement

Parenting

Adolescents
Indonesia has a demographic bonus where the number of young people is quite large than the old generation and children. Youth in Pekanbaru City reached $20,095 \%$ or 234.916 people. The problem is from the preliminary studies results that many adolescents have low emotional intelligence because they are considered less skilled in socializing and are motivated because of social media and electronic media. This study aims to determine the relationship between father involvement in parenting with adolescent emotional intelligence. This research is a quantitative study with a cross-sectional design. The sample in this study was 116 adolescents of Air Cold Village, Bukit Raya Pekanbaru District. Sampling using the Non-Probability technique with the snowball sampling method. Researchers used a questionnaire to collect data. This study uses a bivariate analysis, namely Chi-Square. The results showed that fathers' involvement in parenting was in the high category, namely $92.2 \%$ of 107 people. Kidney intelligence is in the percentage of $82.8 \%$ of 96 people. Thus, there is a positive or significant relationship between fathers' involvement in parenting and adolescent emotional intelligence with a value of $\mathrm{P}=0.008(\mathrm{p}<0.05)$. With these results, it is hoped that nurses can motivate nurses to promote health-related to adolescent psychology through the Youth Family Development Program and the Youth Care Health Program. This is important as an effort to foster adolescent emotional intelligence.

This is an open-access article under the CC-BY-SA license.

\section{Pendahuluan}

Masa remaja adalah periode pertumbuhan dari masa kanak-kanak ke masa dewasa. Tahapan ini merupakan tahap transisi dari kanak-kanak menuju masa dewasa pada usia 11-20 tahun. Fase remaja sering dikenal dengan fase mencari jati diri. Proses pembentukan jati diri pada masa remaja tidak terjadi dalam waktu yang singkat, melainkan remaja harus melakukan proses interaksi dan pengalaman secara berkesinambungan (1)). Data demografi Asia Tenggara tahun 2019 menunjukkan bahwa populasi remaja tertinggi Filipina dengan populasi 67 persen, sedangkan Indonesia populasi remaja pada usia 15 tahun ke atas mencapai 22,27 persen (2). Di Kota Pekanbaru remaja usia diatas 11 tahun mencapai 20,095 persen atau 234.916 jiwa (3). Berdasarkan data tersebut bisa kita lihat banyaknya populasi remaja yang diharapkan menjadi seseorang yang memiliki kecerdasan emosional yang baik. Remaja tidak dapat diprediksi tetapi hal itu merupakan suatu yang normal, sebab pada masa remaja memiliki perubahan suasana hati dan emosi yang melonjak. Kecerdasan emosional merupakan kemampuan remaja untuk 
merasakan, memahami, menerapkan ke pekan emosi sebagai suatu energi, informasi, koreksi serta pengaruh yang manusiawi. Dalam membentuk kecerdasan emosional remaja perlu keterlibatan ayah dalam pengasuhan, manfaat ayah terlibat dalam pengasuhan yaitu perkembangan kognitif, perkembangan emosional, perkembangan sosial dan penurunan perilaku negatif pada remaja. Hal yang negatif jika ayah tidak terlibat dalam pengasuhan yaitu harga diri rendah, pemarah, pemalu, merasa kesepian, cemburuan dan berduka.

Kecerdasan emosional yaitu suatu kemampuan individu untuk bisa memahami serta mengelola emosi diri sendiri maupun orang lain dengan cara yang efektif, sehingga mendapatkan interaksi dan hasil kerja yang lebih produktif (4). Faktor yang mempengaruhi kecerdasan emosional remaja yaitu perubahan jasmani, pola interaksi dengan orang tua, interaksi dengan teman sebaya, pandangan luar dan interaksi dengan sekolah (5). Beberapa penelitian menunjukkan bahwa dari aspek kecerdasan emosional generasi sekarang lebih rendah karena sering kesepian dan pemurung, kurang sopan santun, mudah cemas, gugup dan impulsive (6). Penyebab remaja belum mempunyai kecerdasan emosional yang baik, karena remaja kurang mendapatkan dukungan dari keluarga ataupun orang tua (7).

Keluarga adalah suatu sumber kepribadian seseorang, sebab dalam keluarga ditemukan berbagi elemen dasar untuk membentuk kepribadian seseorang (8). Ayah bertanggung jawab terhadap kebutuhan finansial keluarga atau mencari nafkah sedangkan ibu bertanggung jawab terhadap pengasuhan dasar remaja (9). Himbauan menteri Pendidikan dan Kebudayaan RI pada tahun 2018 lalu, mendorong ayah untuk mengekspresikan diri dalam pengasuhan dan perkembangan anak. Pengasuhan merupakan suatu tanggung jawab yang utama bagi orang tua dalam membuat kedekatan emosional serta aktif dalam memberikan dukungan emosional pada lingkungan remaja (8). Keterlibatan ayah dalam pengasuhan adalah seberapa besar ayah terlibat pada aktivitas yang dilakukan remaja, berkontak langsung dengan remaja, memberikan dukungan finansial dan berapa banyak aktivitas bermain yang dilakukan bersama remaja (10). Peran keterlibatan ayah dalam pengasuhan remaja sangat rendah yaitu 62\% (11). Terlihat dari remaja mengalami permasalahan fisik dan psikologis seperti depresi, nilai akademik menurun serta permasalahan lainnya yang berkaitan dengan pergaulan.

Dampak positif ketika ayah terlibat dalam pengasuhan remaja yaitu remaja lebih senang bersekolah, memiliki sifat yang baik, aktif dalam ekstrakurikuler, sering naik kelas, memiliki Intelligence Quotient (IQ) yang tinggi, remaja sering masuk sekolah, hanya sedikit yang mengalami masalah di sekolah dan dapat memecahkan masalah dengan baik dan benar. Dampak negatif yang ditimbulkan ketika ayah tidak terlibat dalam pengasuhan, yaitu harga diri rendah (self - esteem) ketika remaja menuju dewasa, pemarah (anger), malu (shame) sebab remaja tidak memiliki pengalaman bersama ayah (10). Dampak negatif lainnya yang timbul remaja merasa kesepian (loneliness), cemburu (envy) dan berduka (grief) (12). Kelurahan Air Dingin merupakan kelurahan dengan jumlah remaja terbanyak di Kota Pekanbaru yaitu sebanyak 10.818 orang (13). Berdasarkan hasil penelitian, Perilaku menyimpang remaja Kelurahan Air Dingin disebabkan karena penggunaan media sosial maupun elektronik yang mampu mengubah pola pikir remaja, pengaruh teman sebaya dan kurangnya kontrol orang tua (14).

Hasil studi pendahuluan dengan melakukan wawancara terhadapremaja lima remaja, mengatakan ayahnya memberikan kehangatan, menjadi teladan moral, memenuhi kebutuhan dan memberikan kenyamanan, empat remaja mengatakan ayah sedikit bersifat jujur dan terbuka pada remaja, ayah hanya sedikit menjadi teladan moral bagi remaja, ayah hanya sedikit dekat dengan remaja dan ayah sedikit memberikan kenyamanan bagi remaja. Pada kecerdasan emosional dua remaja mengatakan dapat memahami kesadaran diri, mengarahkan diri, memotivasi orang lain, empati kepada orang lain dan terampil dalam social. Tujuh remaja mengatakan tidak mampu memahami kesadaran diri, tidak mampu untuk memotivasi dirinya sendiri, tidak bisa empati dengan orang lain dalam bergaul dan tidak memiliki keterampilan sosial yang baik dengan orang lain. Hasil wawancara dengan salah satu RW yaitu RW 10 Kelurahan Air Dingin mengatakan remaja kurang sopan seperti suka berkata kasar, pakaian tidak sewajarnya, dan suka kebut- 
kebutan motor di jalan, perilaku ini membuat warga tidak merasa nyaman dengan tindakan remaja tersebut. Penelitian ini bertujuan untuk menilai apakah ada hubungan keterlibatan ayah dalam pengasuhan terhadap kecerdasan emosional remaja. Hasil penelitian ini diharapkan dapat memberikan kontribusi terhadap orang tua, tokoh pendidikan dan masyarakat tentang pola asuh yang tepat sehingga mendukung terwujudnya remaja yang pada masa nantinya menjadi penggerak pembangunan, memiliki kecerdasan emosional yang baik. Harapan peneliti agar peneliti lain melakukan penelitian eksperimen social pada responden.

\section{Metode}

Jenis penelitian pada penelitian ini adalah deskriptif kuantitatif, dengan pendekatan cross sectional study. Variabel independen adalah keterlibatan ayah dalam pengasuhan dengan sub variabel Paternal Engagement, Accessibility dan Responsibility, sedangkan variabel dependen yaitu kecerdasan emosional dengan sub variabel kesadaran diri, pengaturan diri, motivasi, empati dan keterampilan social remaja. Sebelum melakukan penelitian, terlebih dahulu peneliti melakukan uji etik dengan nomor surat 342/KEPK/STIKes-HTP/VI/2020 dan setelah itu peneliti melakukan uji validitas. Uji validitas dilakukan di Kelurahan Tangkerang Labuai Kecamatan Bukit Raya Kota Pekanbaru pada remaja yang berusia 11 - 20 tahun. setelah dilakukan uji validitas, dari 20 pernyataan keterlibatan ayah dalam pengasuhan, didapatkan 14 pernyataan valid dan enam pernyataan tidak valid. Untuk pernyataan kecerdasan emosional, dari 20 pernyataan didapatkan 12 pertanyaan valid dan delapan tidak valid. Hal ini berdasarkan perhitungan, terlihat untuk variabel keterlibatan ayah dalam pengasuhan nilai $r(0,391-0,730)$ dan kecerdasan emosional $r$ $(0,363-0,665>r$ tabel $(0,361)$.

Uji validitas yang telah dilakukan selanjutnya dilakukan pengukuran relibilitas data. Mengukur kasus yang sama dengan menggunakan satu alat ukur dengan menggunakan dua kali dan hasilnya relatif konsisten, maka alat ukur tersebut dikatakan reliabel. Hasil reliabilitas pada keterlibatan ayah dalam pengasuhan diperoleh nilai alpha cronboch's yaitu 0,795 $>$ dari pada 0 , 60. Sedangkan reliabilitas kecerdasan emosional diperoleh nilai alpha cronboch's 0,712 > dari pada 0.60 (15). Pada penelitian ini populasi adalah remaja usia 11 - 20 tahun yang berada di Kelurahan Air Dingin Kecamatan Bukit Raya Kota Pekanbaru yang berjumlah 10.818 remaja. Jumlah sampel berjumlah 116 remaja. Jenis teknik sampling yang digunakan pada penelitian ini yaitu non probability sampling (sample non-random) dengan metode snowball sampling. Menurut (15) snowball sampling adalah pengambilan sampel berantai, kemudian sampel satu yang didapatkan datanya diminta menunjuk teman yang lain yang berkaitan dengan judul penelitian sampai pada data yang diperoleh cukup.

Insterumen penelitian yang digunakan adalah angket/ kuesioner dengan cara checklist. Keterlibatan ayah dalam pengasuhan menggunakan skala likert pernyataan positif sangat setuju $(\mathrm{SS})=4$, setuju (S) $=3$ tidak setuju $(\mathrm{TS})=2$ dan sangat tidak setuju (STS) $=1$. Pernyataan negatif sangat setuju (SS) $=1$ setuju $(\mathrm{S})=2$, tidak setuju $(\mathrm{TS})=3$ dan sangat tidak setuju (STS) $=4$. Skoring jika dikatakan tinggi $>42$ dan sedang 28 - 42. Pada pernyataan kecerdasan emosional sama menggunakan skala likert. Kecerdasan emosional tinggi > 36 dan sedang $24-36$. Peneliti kemudian melakukan pengolahan data melalui prgram komputer. Peneliti menganalisis data yang meliputi analisa univariat dan bivariat dengan uji statistik yang digunakan adalah uji Chi Square fisher's exact test.

\section{Hasil dan Pembahasan}

Hasil penelitian yang dilakukan pada bulan Juli sampai Agustus 2020 dengan 116 responden pada remaja yang ada di Kelurahan Air Dingin Kecamatan Bukit Raya Kota Pekanbaru. Data yang diperoleh sebagaimana pada table 1 . 
Tabel 1. Distribusi Frekuensi Usia, Jenis Kelamin dan Pekerjaan Ayah

\begin{tabular}{lll}
\hline \multicolumn{1}{c}{ Variabel } & $\boldsymbol{F}$ & $\%$ \\
\hline Usia & & \\
$\quad$ Remaja awal $(11-14$ tahun) & 55 & $47,4 \%$ \\
Remaja madya (15 - 17 tahun) & 37 & $31,9 \%$ \\
$\quad$ Remaja akhir (18 - 20 tahun) & 24 & $20,7 \%$ \\
Jenis Kelamin & 69 & $59,5 \%$ \\
$\quad$ Laki - laki & 47 & $40,5 \%$ \\
$\quad$ Perempuan & 111 & $95,7 \%$ \\
Pekerjaan Ayah & 5 & $4,3 \%$ \\
$\quad$ Perkerja (PNS, Swasta, Wiraswasta dan lainnya). & & \\
$\quad$ Tidak Perkerja (Pensiun dan lainnya). & 9 & $7,8 \%$ \\
Keterlibatan ayah dalam pengasuhan & 107 & $92,2 \%$ \\
$\quad$ Sedang & & \\
$\quad$ Tinggi & 20 & $17,2 \%$ \\
Kecerdasan Emosional & 96 & $82,8 \%$ \\
$\quad$ Sedang & & \\
Tinggi &
\end{tabular}

Pada tabel 1 diperoleh data responden berdasarkan usia yang terbanyak yaitu usia $11-14$ tahun $(47,4 \%)$, lebih dari separuh berjenis kelamin laki - laki $(59,5 \%)$ dan pekerjaan ayah remaja sebagian besar sebagai pegawai/karyawan baik pegawai negeri sipil, swasta, wiraswasta $(95,7 \%)$. Variabel keterlibatan ayah dalam pengasuhan dengan kategori tinggi terdapat $92,2 \%$ dan kecerdasan emosional kategori tinggi yaitu $82,8 \%$. Penelitian ini sejalan dengan penelitian yang mengungkapkan bahwa usia remaja memiliki emosi yang labil, pengalaman emosi yang ekstrim dan selalu merasa mendapatkan tekanan dengan adanya hubungan yang dekat ayah membuat remaja mempersepsikan ayah secara positif, sehingga remaja cenderung menjadikan ayah sebagai model baik dalam bersifat dan berperilaku. Pengasuhan dapat mempengaruhi keseluruhan perkembangan sosial, emosional dan prestasi akademik remaja (16). Penelitian lain mengemukakan bahwa pekerjaan tidak mengganggu ayah terlibat dalam pengasuhan remaja. Ayah yang bekerja rata - rata enam jam masih memiliki waktu yang dapat digunakan untuk berinteraksi dengan remaja (17).

Kedekatan antara ayah dan remaja dalam melakukan komunikasi yang baik, dapat menciptakan suasana yang nyaman bagi remaja agar remaja berani mengungkapkan perasaan dan permasalahan yang sedang dihadapinya (9). Hal ini sejalan dengan penelitian yang menyatakan bahwa keterlibatan ayah mempengaruhi perkembangan remaja, di mana ayah memberikan perhatian dan dukungan yang menimbulkan perasaan diterima, diperhatikan serta menumbuhkan rasa percaya diri pada remaja (18). Indikator variabel penelitian ini terbagi tiga yaitu paternal engagement, accessibility dan responsibility. Dari hasil penelitian (lihat tabel 2), Pada penelitian ini terlihat indikator keterlibatan ayah dalam pengasuhan yang dominan adalah paternal engagement yaitu yang tinggi sebanyak 96,6\% kemudian responsibility sebanyak 95,7\% dan accessibility tinggi 70,7\% . Hal ini sejalan dengan penelitian yang dilakukan oleh (19), mendapatkan hasil indikator tertinggi yaitu paternal engagement dengan hasil 76, 41\%. Paternal engagement adalah merupakan waktu yang dihabiskan ayah dan remaja dalam melakukan interaksi langsung. Kedekatan antara ayah dan remaja dalam melakukan komunikasi yang baik, dapat menciptakan suasana yang nyaman bagi remaja sehingga berani mengungkapkan perasaan dan permasalahan yang sedang dihadapinya (9) 
Tabel 2. Distribusi Keterlibatan Ayah dan Kecerdasan Emosional Anak

\begin{tabular}{|c|c|c|}
\hline Sub Variabel & $F$ & $\%$ \\
\hline \multirow{2}{*}{\multicolumn{3}{|c|}{$\begin{array}{l}\text { Keterlibatan ayah dalam pengasuhan } \\
\text { Engaqement }\end{array}$}} \\
\hline & & \\
\hline Tinggi & 112 & 96,6 \\
\hline Rendah & 4 & 3,4 \\
\hline \multicolumn{3}{|l|}{ Accessibility } \\
\hline Tinggi & 83 & 70,7 \\
\hline Rendah & 34 & 29,3 \\
\hline \multicolumn{3}{|l|}{ Responsibility } \\
\hline Tinggi & 111 & 95,7 \\
\hline Rendah & 5 & 4,3 \\
\hline \multicolumn{3}{|l|}{ Kecerdasan emosional Kesadaran diri } \\
\hline Tinggi & 62 & 53,4 \\
\hline Rendah & 54 & 46,6 \\
\hline \multicolumn{3}{|l|}{ Pengaturan diri } \\
\hline Tinggi & 32 & 27,1 \\
\hline Rendah & 84 & 72,4 \\
\hline \multicolumn{3}{|l|}{ Motivasi } \\
\hline Tinggi & 82 & 70,7 \\
\hline Rendah & 34 & 29,3 \\
\hline \multicolumn{3}{|l|}{ Empati } \\
\hline Tinggi & 67 & 57,8 \\
\hline Rendah & 49 & 42,2 \\
\hline \multicolumn{3}{|l|}{ Keterampilan sosial } \\
\hline Tinggi & 115 & 99,1 \\
\hline Rendah & 1 & ,9 \\
\hline
\end{tabular}

Hasil analisis kuesioner kecerdasan emosional diperoleh indikator yang dominan adalah keterampilan sosial. Hal ini sejalan dengan hasil penelitian yang juga mengungkapkan indikator kecerdasan emosional yang paling dominan yaitu keterampilan social (20). Keterampilan sosial merupakan kemampuan untuk memahami emosi dengan baik ketika berhubungan dengan orang lain. Keterampilan sosial yang paling berguna bagi remaja yaitu keterampilan kepemimpinan, kolaborasi dengan orang lain dan menciptakan sinergi kelompok sesama remaja. Remaja yang memiliki EQ yang tinggi akan lebih memahami, berempati dan bernegosiasi dengan orang lain dalam ekonomi global (21). Juga sejalan dengan penelitian lain yang menemukan bahwa keberhasilan remaja tidak hanya ditentukan oleh kemampuan kognitif, tetapi ditentukan pula oleh kecerdasan emosional (22). Individu yang memiliki IQ tinggi lebih berhasil jika sejalan dengan kecerdasan emosional. Hal ini sejalan dengan teori yang dilakukan (23), kecerdasan emosional bagian dari kecerdasan sosial yang melibatkan kemampuan memantau perasaan sosial dan orang lain serta dapat memilah - milah informasi untuk berpikir dan bertindak.

Berdasarkan tabel 3 didapatkan sebesar 79,3\% responden mendapatkan pengasuhan dengan keterlibatan tinggi dari ayah dan memiliki kecerdasan emosional tinggi dengan kategori tinggi. Kecerdasan emosional dengan kategori sedang lebih sedikit pada remaja dengan keterlibatan ayah dalam pengasuhan dengan kategori sedang $(4,3 \%)$ dibandingkan yang keterlibatan ayahnya tinggi $(12,9 \%)$. Hasil uji statistik menggunakan chi - square fisher's exact test dengan menujukan nilai $P$ value $=0,008(p<0,05)$. Dari hasil tersebut dapat ditarik kesimpulan bahwa ada hubungan positif yang signifikan antara keterlibatan ayah dalam pengasuhan dengan kecerdasan emosional remaja. Penelitian ini sejalan dengan nilai penelitian Syarifah (2012) yang juga menyimpulkan bahwa ada hubungan positif yang signifikan antara persepsi keterlibatan ayah dalam pengasuhan dengan kematangan emosi pada remaja (16). Semakin positif persepsi keterlibatan ayah dalam pengasuhan maka akan semakin tinggi tingkat kematangan emosi remaja, sedangkan semakin 
negatif persepsi terhadap keterlibatan ayah dalam pengasuhan maka semakin rendah tingkat kematangan emosi remaja. Penelitian lain menyimpulkan bahwa ada hubungan antara keterlibatan ayah dalam pengasuhan dengan kecerdasan emosional remaja (24). Hal ini sesuai dengan teori yang menyebutkan manfaat keterlibatan ayah dalam pengasuhan dapat membentuk remaja memiliki kecerdasan emosional yang baik misalnya remaja memiliki sifat yang baik, bisa mengontrol diri, dapat menyelesaikan masalah dan lain-lainnya (10).

Tabel 3. Hubungan Keterlibatan Ayah dalam Pengasuhan dengan Kecerdasan Emosional Remaja

\begin{tabular}{|c|c|c|c|c|c|c|c|}
\hline \multicolumn{8}{|c|}{ Kecerdasan emosional } \\
\hline \multirow{2}{*}{ Keterlibatan ayah dalam pengasuhan } & \multicolumn{2}{|c|}{ Sedang } & \multicolumn{2}{|c|}{ Tinggi } & \multicolumn{2}{|c|}{ Total } & \multirow[t]{2}{*}{ P value } \\
\hline & $N$ & $\%$ & $N$ & $\%$ & $N$ & $\%$ & \\
\hline Sedang & 5 & $4,3 \%$ & 4 & $3,4 \%$ & 9 & $7,8 \%$ & 0,008 \\
\hline Tinggi & 15 & $12,9 \%$ & 92 & $79,3 \%$ & 107 & $92,2 \%$ & \\
\hline
\end{tabular}

Ayah yang terlibat dalam pengasuhan untuk anak perempuan akan dapat membuat remaja putri terhindar dari hubungan berpacaran yang tidak sehat karena ia dapat menghargai dirinya sendiri dan untuk remaja laki - laki akan sangat kecil terjebak dalam masalah kenakalan remaja (25). Hal ini berbeda dengan penelitian yang dilakukan Muna (2015), menyatakan peran ayah pada remaja perempuan dan remaja laki - laki tidak berbeda (26). Dunia luar atau masyarakat masih menetapkan nilai-nilai yang berbeda antar remaja laki-laki dan remaja perempuan. Kalau remaja laki - laki mempunyai banyak teman berarti mendatangkan kebanggaan, sedangkan jika remaja perempuan mempunyai banyak teman mendapatkan predikat kurang baik. Penerapan nilai semacam ini yang membuat remaja merasa dibedakan, jika tidak diberikan pengertian dengan bijak menyebabkan remaja bertingkah laku emosional Menurut (5).

Kecerdasan emosional remaja yang tinggi juga dipengaruhi oleh faktor pembawaan yang bersifat genetik (27). Hal ini didukung oleh teori yang mengatakan sifat - sifat yang dimiliki remaja merupakan warisan dari keluarga terutama ayah, misalnya sifat penyabar, pemarah, kikir, pembosan dan hemat (28). Penelitian lain menjelaskan bahwa keterlibatan ayah dalam pengasuhan dan kecerdasan emosional memiliki hubungan yang sangat signifikan terlihat dari remaja yang merasakan dukungan dari ayah maka memiliki sifat yang baik (29).

Dalam membentuk kecerdasan emosional remaja dibutuhkan keterlibatan ayah dalam pengasuhan dan juga pihak keluarga. Perlu memberikan dukungan kepada ayah agar terlibat dalam pengasuhan untuk membentuk pertumbuhan dan perkembangan remaja. Terutama perkembangan emosional pada remaja agar dapat menggunakan emosi baik di lingkungan keluarga, sekolah maupun lingkungan luar. Kecerdasan emosional wajib dimiliki remaja agar menjadi generasi yang sukses, oleh sebab itu ayah harus terlibat dalam pengasuhan. Istri perlu mendukung suami agar mau terlibat dalam pengasuhan untuk membentuk generasi yang cerdas dan sukses.

\section{Kesimpulan}

Penelitian ini menemukan hubungan yang signifikan antara keterlibatan ayah dalam pengasuhan terhadap kecerdasan emosional remaja. Berdasarkan analisis bivariat yang dilakukan, didapatkan hasil chi - square fisher's exact test dengan $\mathrm{P}$ value $=0,008(\mathrm{p}<0,05)$. Dari hasil univariat pada penelitian ini ditemukan responden mayoritas berusia 11 - 14 tahun, mayoritas berjenis kelamin laki - laki dan profesi ayah mayoritas sebagai pegawai/karyawan.

\section{Ucapan Terimakasih}

Para penulis mengucapkan terimakasih kepada reviewer yang telah membantu penulis untuk meningkatkan kualitas artikel ini, terima kasih juga penulis sampaikan kepada STIKes Hang Tuah 
Pekanbaru yang telah mensupport penelitian ini.

\section{Konflik Kepentingan}

Menyatakan konflik kepentingan, "Penulis menyatakan tidak ada konflik kepentingan."

\section{Referensi}

1. Wong., Hockenberry, M., \& Wilson D. Essentials of padiatric nursing. ninth edit, editor. america: elsevies; 2013. 450-461 p.

2. Statistik BP. Statistik Indonesia 2019. Jakarta: BPS; 2019.

3. Badan Pusat Statistik. Kota pekanbaru dalam angka Pekanbaru municipality in figures 2019. Pekanbaru: BPS; 2019.

4. Saam, Z., \& Wahyuni S. Psikologi keperawatan. Jakarta: Rajawali Pers; 2014. 56-71 p.

5. Ali, M., \& Asrori M. Psikologi remaja perkembangan peserta didik. Jakarta: PT Bumi Aksara.; 2012. 9-75 p.

6. Tirtayani, L. A., Asril, N. M., \& Wirya N. Perkembangan sosial emosional pada anak. Yogyakarta: Graha ilmu; 2014.

7. Purba R, Harahap KNP. Hubungan Fungsi Afektif Keluarga Dengan Kecerdasan Emosional Remaja Di Sma Negeri 1 Kecamatan Panai Hulu Kabupaten Labuhan Batu Tahun 2019. J Penelit Keperawatan Med. 2019;1(2):53-7.

8. $\quad$ sri lestari. psikologi keluarga. 2012. 37 p.

9. Allgood SM, Beckett TE, Peterson C. The role of father involvement in the perceived psychological weil-being of young adult daughters: A retrospective study. $\mathrm{N}$ Am J Psychol. 2012;14(1):95-110.

10. Sunarsih T. Tumbuh kembang anak. Bandung. Bandung: PT. Remaja Rosdakarya; 2018.

11. Septiani D, Nasution IN. Peran Keterlibatan Ayah dalam Pengasuhan Bagi Perkembangan Kecerdasan Moral Anak. J Psikol. 2018;13(2):120.

12. Lerner H. Losing a father too early. America: The Dance Of Connection; 2011.

13. Badan Pusat Statistik. Kecamatan Bukit Raya dalam angka 2019. Pekanbaru: BPS; 2019.

14. Piliang, R. I. Perilaku menyimpang dikalangan remah kelurahan air dingin. JOM FISIP. 2018;5(II):1-15.

15. Donsu JDT. Metodologi penelitian keperawatan. Yogyakarta: Pustaka Baru Press; 2017.

16. Syarifah H, Widodo P., Kristiana I. Hubungan Antara Persepsi Terhad " p Keterlibatan Ayah Dalam Pengasuhan Dengan Kematangan Emosi Pada Remaja di SMA Negeri " X ". Proceeding Temu Ilm Nas VIII IPPI. 2012;8(10):230-8.

17. Hidayati F, Kaloeti DVS, Karyono. Peran Ayah dalam Pengasuhan Anak [Role of Father in Parenting]. J Psikol UNDIP. 2011;9(1):1-10.

18. Astuti V, Masykur AM. Pengalaman Keterlibatan Ayah Dalam Pengasuhan Anak (Studi Kualitatif Fenomenologis). J Empati. 2015;4(2):63-70.

19. Marhamah, Ria, N. \& F. Gambaran peran ayah dalam pengasuhan Kecamatan Bukit Raya Kota Pekanbaru. J Online Mhs Fak Kegur Dan Ilmu Pendidik Univ Riau. 2017;2(3):1-3.

20. Afero B. Peran kecerdasan emosional sebagai faktor yang mempengaruhi kemandirian belajar siswa ( The role of emotional intelligence as a factor in affecting student independence learning ). J Pendidik Manaj Perkantoran. 2016;1(1):215-23.

21. Habeeb KT. Emotional intelligence, social intelligence, locus of control in relation to stress 
management in adolescents. India: Laxmi Book Publication; 2016.

22. Tazkiyah, N., \& Sondang MJS. Hubungan kecemasan dan kecerdasan emosional dengan kecenderungan perilaku agresivitas anak jalanan di sekolah master indonesia depok. J IKRAITH Hum. 2020;4(2).

23. Astria, P. V. Mengembangkan kecerdasan spiritual anak melalui pembelajaran membaca sastra. malang: UB Press; 2014.

24. Dewi S, Kristiana IF. Pengasuhan Dengan Kecerdasan Emosional Pada Siswa Laki-Laki Kelas X Smk Negeri 4 Semarang. J Empati. 2017;6(Nomor 4):107-11.

25. Astuti V. Keterlibatan Ayah Dalam Pengasuhan Jarak Jauh Remaja. Pros Semin Nas Parent 2013. 2013;121-31.

26. Muna LN, Sakdiyah EH. Pegaruh Peran Ayah terhadap Determinasi Diri Remaja. Psikoislamika. 2015;12(1):1-17.

27. Wulandari D. Gambaran kecerdasan emosional pada siswa SMKN 1 Jakarta. J Pendidik dan Pengukuran Psikol. 2012;1(1):183-90.

28. Thaib MI. Perkembangan jiwa agam pada masa al - murahiqah (remaja). J Psikol. 2015;17(2):245-58.

29. AROFAL HAQUE E. Hubungan Antara Keterlibatan Ayah Dalam Pengasuhan Dan Kecerdasan Emosional Dengan Perilaku Prososial Pada Remaja. Character J Penelit Psikologi. 2013;2(1):1-9. 